\title{
THERMAL ANALYSIS OF ORIENTAL BEECH SAWDUST TREATED WITH SOME COMMERCIAL WOOD PRESERVATIVES
}

\author{
Ergun Baysall,s, Ilyas Deveci², Turkay Turkoglu ${ }^{3}$,Hilmi Toker ${ }^{1}$
}

\begin{abstract}
In this study, investigation of the thermal properties of Oriental beech (Fagus orientalis) sawdust treated with 0,$25 ; 1$ and $4,70 \%$ aqueous solutions of Adolit KD-5, Wolmanit CX- 8 and Tanalit-E were performed by using thermogravimetric analysis, differential-thermal analysis, and differential-thermal analysis under argon atmosphere.

Results were compared with the untreated wood (control). It was found that the treatment with Adolit KD-5, Wolmanit CX- 8 and Tanalit-E decreased the $\mathrm{T}_{\max }$ (maximum degradation temperature) and increased residual char amount with respect to the control sample. Increases in the concentration of applied preservatives promote the char formation. It was found that the char content after pyrolysis experiment had good agreement with the boric acid amount in wood preservatives.
\end{abstract}

Keywords: Differential-thermogravimetry, Fagus orientalis, thermogravimetric analysis, differential-thermal analysis, residual char.

\section{INTRODUCTION}

Wood is an important renewable material with excellent physical and mechanical properties (Salca and Hiziroglu 2014). It has been extensively used for aesthetic, engineering, and structural applications (Bhat et al. 2010, Lesar et al. 2011). As wood is a natural organic material, it is subject to biological and non-biological factors such as insects like termites, decay fungi, mould, weathering, and fire in application fields. Thus, wood products require protection from these factors in order to provide reliable service. Wood protection technology generally involves the modification of wood products to improve protective properties. The most commonly used method of wood protection is chemical treatment which involves the impregnation of chemical substances into the wood (Poncsák et al. 2006, Ajuong and Pinion 2010). Preservative treatment is effective and can extend the service life of wood and wood products (Ahmed and Moren 2012). However, use of many of the effective poisonous chemicals is also questionable. Increased public concern on health and the environmental effects of many wood preservatives have emerged. The focus on copper-based preservatives has increased following concerns about environmental effects of chromium and arsenic and resulting restrictions on the use of chromated copper arsenate (CCA) (Freeman and McIntyre 2008). Chromated copper arsenate (CCA) has been used for wood preservation for more than 30 years but in the last decade the use of CCA has been restricted in Europe, North America, and Japan due to its toxicity against humans, animals, and environment (Palanti et al. 2011). Many of the alternative preservatives contain copper as their active ingredient against fungal decay. Copper compounds are very effective against numerous fungi and are the basis of numerous formulations of wood preservatives (Mourant et al. 2008). They

\footnotetext{
${ }^{1}$ Department of Wood Science and Technology, Faculty of Technology, Mugla Sitki Kocman University, Kotekli, Mugla, Turkey. ${ }^{2}$ Selçuk University, Vocational School of Technical Sciences, Chemistry and Chemical Processing Technologies, Konya, Turkey ${ }^{3}$ Department of Forestry, Koycegiz Vocational School, Mugla Sitki Kocman University, Koycegiz, Mugla, Turkey.

•Corresponding author: ergun69@yahoo.com
}

Received: 30.05.2016 Accepted: 29.03.2017 
also have advantages: it is relatively easy to create waterborne formulations; it is easy to analyze and determine penetration in wood, and copper slows photodegradation by UV radiation and water (Archer and Preston 2006). At present, the new generation of copper containing preservatives such as Tanalith-E (TN-E) and adolit-KD5 (AD KD-5) are being used in the forest products industry instead of CCA (Turkoglu et al. 2015). They are copper salts with others "co-formulating" substances, such as boron, azoles and organic compounds (Palanti et al. 2008). It is generally known that new copper containing wood preservatives protect wood against fungal decay and insects and prevent photodegradation. However, there are not enough systematic studies on fire retardancy of preservative treated wood. Most of the preservatives include copper and chromium ions which can promote glow combustion and they also include boric acid and its derivatives used in fire reterdants. So, wood preservatives can have positive or adverse affects on thermal properties of woods. Fundamentally, wood has been used in house interiors, building or public transport constitutes a potential hazard for people in case of fire (Gao et al. 2005). Therefore, knowledge of the thermal degradation and fire performance of wood treated with these chemicals can be critical (White and Dietenberger 2001) and attract more attention than ever before in order to comply with the safety requirements (Lowden and Hull 2013, Jiang et al. 2015).

Various methods have been developed for evaluating the effectiveness of fire retardant treated wood and the most common of them; thermal analysis is a simple, convenient, reproducible and fast method for evaluating the pyrolysis and flame retardants under air or inert gas flow ( Liodakis et al. 2003, Tsujiyama and Miyamori 2000). Thermal decomposition characteristics of wood components are different because of differences in their chemical structure. Hemicellulose, cellulose, and lignin decompose in distinctive temperature range. Hemicellulose decomposes easily with respect to other components of wood. It decomposes at temperature between $200-280^{\circ} \mathrm{C}$ (Sinha et al. 2000). In temperature range between $250-300^{\circ} \mathrm{C}$, the other main components of the wood products (lignin and cellulose) degrade (Salman et al. 2014). It was reported that the wooden materials generally separate into three stages during the pyrolysis. First stage is removal of volatile parts below $200^{\circ} \mathrm{C}$; second stage is degradation of hemicelluloses, celluloses, and lignin between $200-378^{\circ} \mathrm{C}$; and third stage is conversion of nonvolatile and noncombustible part into tar and char, up to $600^{\circ} \mathrm{C}$. Wood is exposed to thermal degradation reactions under the effect of increased temperatures using differential thermal analysis (DTA) and thermogravimetry (TG) techniques at heating rates 20 and $30{ }^{\circ} \mathrm{C} \mathrm{min}-1$ in temperature range $30-650{ }^{\circ} \mathrm{C}$ (Kiziltas et al. 2011, Gao et al. 2004, Wielage et al. 1999). The temperatures at which decomposition reactions of wood start and the changes in sample weight with the reactions can be followed (Yorulmaz and Atimtay 2009). The thermal conversion process is generally conducted in a chamber in one of the three ways; pyrolysis, gasification, and combustion or incineration (Chandrasekaran and Hopke 2012, Helsen and Van den Bulck 2005). Pyrolysis is defined as the thermal degradation of carbonaceous materials in the absence of oxygen and is a possible thermochemical conversion (Di Blasi 2008, Chandrasekaran and Hopke 2012). The mechanism of fire retardant efficiency can be well understood by studying the pyrolysis process of wood treated with fire retardants. Using the fire-retardant chemicals can cause pyrolysis reactions to form more char and water, and therefore reduce the temperature of the pyrolysis as well as reduce the yield of the flammable gases (Yunchu et al. 2000). Thermogravimetric analysis studies were carried out by several researchers about thermal degradation of wood treated with fire retardant chemicals (Yunchu et al. 2000, Baysal 2002, Jiang et al. 2010, Tomak et al. 2012, Jiang et al. 2015). Deka et al. (2002) investigated the resistant capacity of a chemically treated hard wood, Anthocephalus cadamba (Roxb) Miq. to thermal degradation using TGA and DTG techniques. They found that treated wood was thermally more stable than the untreated wood. Wu et al. (2014) researched flame retardancy and thermal degradation behavior of red gum wood treated with hydrated magnesium chloride. They reported that treatment with hydrated magnesium chloride decreased flame intensity and heat release rate, and reduced smoke concentration and gas yield. Uner et al. (2016) investigated thermal behaviour of borate treated Oriental beech wood. They found that borate treatment decreased the $\mathrm{T}_{\max }$ (maximum degradation temperature) and increased residual char amount. Higher concentration levels of borates resulted in higher char content of Oriental beech wood specimens. Wang et al. (2004) studied thermal characteristics of basswood (Tilia amuresis) impregnated with boric acid. They found that treatment of wood with boric acid resulted in increased weight loss at lower temperatures and decreased weight loss at higher temperatures.

Wood products are commonly used materials in daily life. Generally, wood products are used as its treated form because of durability and cosmetic concern. Most chemicals used as preservatives and 
coatings affect the thermal behavior of wood. So, it is crucial to have knowledge about the effect of heat on treated woods. Thermal behavior of wood is crucial because of safety and statutory regulations so, the research's have to be performed for each chemical used as preservatives or another purposes. Thermal behaviour of Oriental beech (Fagus orientalis) wood treated with aqueous solutions of Adolith KD 5, Wolmanit CX 8 and Tanalith -E have not been investigated yet in literature The aim of this study is to evaluate the thermal behavior of Oriental beech wood treated with $0,25 \%$, $1 \%$, and $4.70 \%$ aqueous solutions of Adolith KD 5, Wolmanit CX 8 (WCX-8), and Tanalith-E by thermogravimetry analysis (TGA), differential thermogravimetry (DTG), and differential thermal analysis (DTA).

\section{MATERIALS AND METHODS}

\section{Materials}

Sapwood of Oriental beech (Fagus orientalis L.) timber free of knots, excessive cross-grain, and other obvious defects was obtained from Yucel Wood Products Industry, located in Mugla, the South West region of Turkey. Oriental beech timber was machined into narrow strips. The strips were carefully chosen for having the same annual ring and then cut into small pieces prior to milling. Wood flour was prepared by grinding the small wood pieces in a Wiley mill. Diameter of obtained particles was smaller than the $288 \mu \mathrm{m}$. AD KD-5, WCX-8, and TN-E were used as impregnation chemicals. Before impregnation, the samples were conditioned at $65 \%$ relative humidity and $20^{\circ} \mathrm{C}$ for two weeks.

\section{Impregnation method}

Aqueous solutions of the wood preservatives having concentration of $0,25 \%, 1 \%$, and $4,70 \%$ were prepared using distilled water for the impregnation procedure. The wood flour approximately $100 \mathrm{~g}$ was immersed in the solutions at $60^{\circ} \mathrm{C}$ for $2 \mathrm{~h}$. Samples were collected by filtration and the treated wood samples were subsequently dried at $60^{\circ} \mathrm{C}$ until they had the unchangeable weight. Similar impregnation procedure of wood flour and wood samples is described in TG and DTA studies on fire retardant treated wood by Jiang et al. (2010) and Yunchu et al. (2000). The treated wood samples were then moisture conditioned for two weeks at $20^{\circ} \mathrm{C}$ and $65 \%$ relative humidity.

\section{Thermal analysis}

Thermogravimetry analysis (TGA), differential thermogravimetry (DTG), and differential thermal analysis (DTA) were carried out under argon at a heating rate of $10^{\circ} \mathrm{C} / \mathrm{min}$ and a purge rate of $50 \mathrm{~mL} / \mathrm{min}$ using a LABSYS TG-DTA analyzer (France). The temperature was heated from the room temperature to $600^{\circ} \mathrm{C}$. During the heating and pyrolysis of about $10 \mathrm{mg}$ of sample, the weight loss was monitored continuously. Onset and inflection temperatures of the pyrolysis were recorded by the analyzer for each treatment group. The rate of weight loss as a function of time was derived from $\mathrm{TG}$ curve resulting in a derivative TG curve.

\section{RESULTS AND DISCUSSIONS}

Commercial wood preservatives include numerous chemicals that affect the final properties of the woods. The composition of AD KD-5, WCX-8, and TN-E were listed in Table1. 
Table 1. Composition of the commercial wood preservatives.

\begin{tabular}{|c|c|}
\hline Wood preservatives & Component (amount \%) \\
\hline AD KD-5 & $\begin{array}{l}\text { Copper(II)hydroxidecarbonate } 20,33 \% \\
\text { Didecylpolyoxoethylammoniumborate } 10 \% \\
\text { Boric acid } 8 \% \\
\text { Alpha-iso-Tridecyl-omega-hydroxy-polyglycolether } 1-2,5 \%\end{array}$ \\
\hline WCX-8 & $\begin{array}{l}\text { Bis-(N-cyclohexyldiazeniumdioxy)-copper } 2,8 \% \\
\text { Copper hydroxide carbonate } 13,04 \% \\
\text { Boric acid } 4,0 \% \\
\text { 2-Aminoethanol } 20-40 \%\end{array}$ \\
\hline TN-E & $\begin{array}{l}\text { Copper carbonate } 20,5 \% \mathrm{w} / \mathrm{w} \\
2 \text {-aminoethanol }<20 \% \mathrm{w} / \mathrm{w} \\
\text { Boric acid }<5 \% \mathrm{w} / \mathrm{w} \\
\text { Tebuconazole }<20 \% \mathrm{w} / \mathrm{w} \\
\text { Organic acid }<5 \% \mathrm{w} / \mathrm{w} \\
\text { Polyethyleneamine }<20 \% \mathrm{w} / \mathrm{w} \\
\text { Surfactant }<5 \% \mathrm{w} / \mathrm{w}\end{array}$ \\
\hline
\end{tabular}

The TG curves, first derivative of TG curves (DTG) and DTA curves of Oriental beech wood treated with $(0,25 \% ; 1 \%$ and $4,70 \%)$ AD KD-5, WCX-8, and TN-E are shown in Figure 1. The obtained results were compared with the non-treated Oriental beech wood called as control. The temperature of the initial weight loss of pyrolysis $\left(\mathrm{T}_{\mathrm{i}}\right)$, maximum degradation temperature $\left(\mathrm{T}_{\max }\right)$ and residual char content are given in Table 2 .
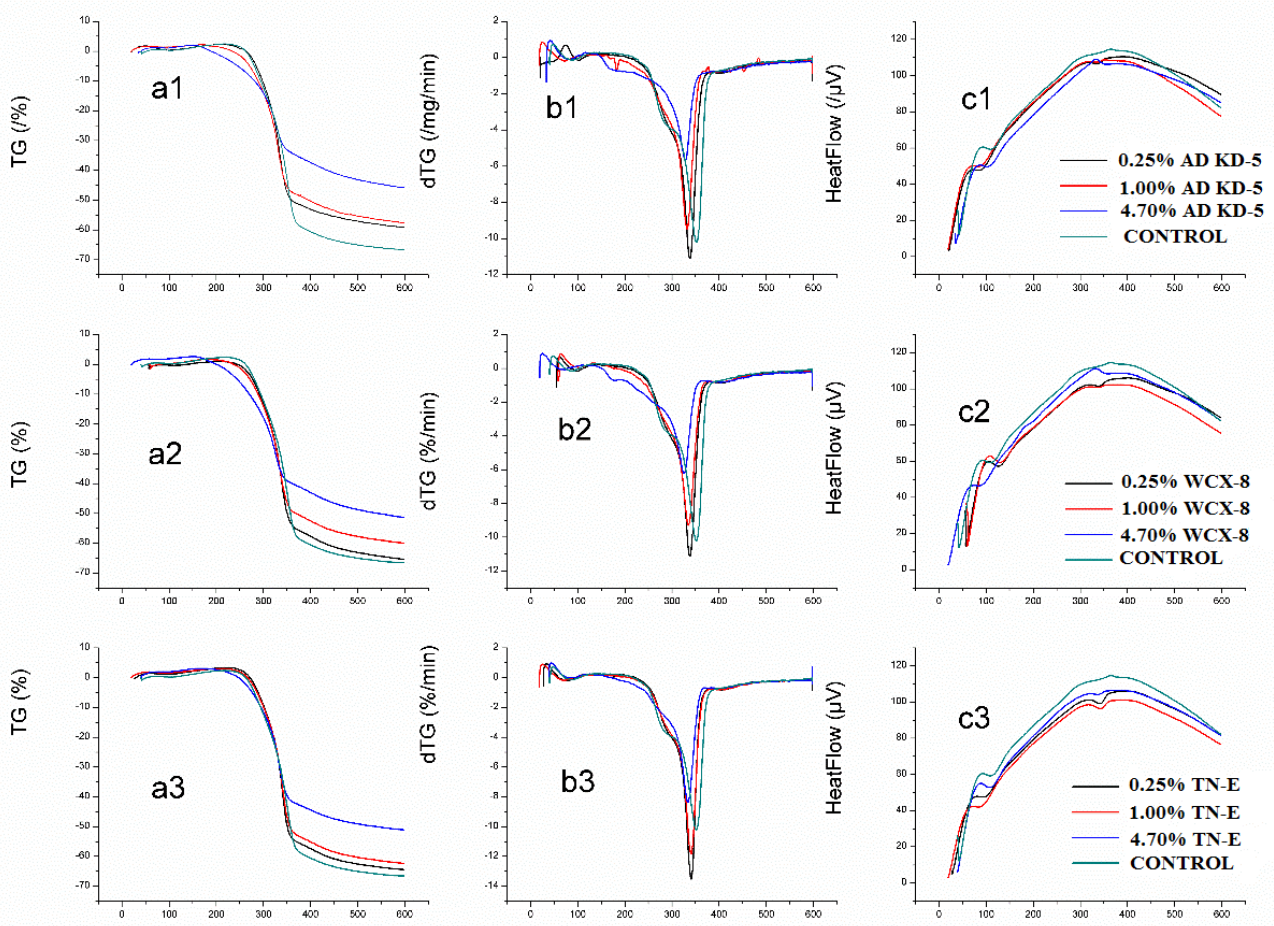

Furnance Temperature ${ }^{\circ} \mathrm{C}$

Figure 1. TG curves (a1, a2, a3), first derivative of TG curves (TGA) (b1, b2 and b3) and DTA (c1, c2, c3) curves of (1) AD KD-5, (2) WCX-8 and (3)TN-E impregnated Oriental beech wood with different concentrations $(0,25 \% ; 1 \%$ and $4,70 \%)$. 
As seen in Figure 1, there was no significant weight loss observed in TG and DTG curves for the control sample below $200^{\circ} \mathrm{C}$. At nearly $110^{\circ} \mathrm{C}$, endothermic peak corresponds to evaporation of physically bound water was observed from the DTA curves. Sharp decrease observed in TG curves between $231-350^{\circ} \mathrm{C}$ for the untreated sample could be related to the degradation of cellulose, hemicelluloses, and lignin. As mentioned before, hemicellulose decomposed easily with respect to the other components. Pyrolysis of hemicellulose results in formation of $\mathrm{CO}, \mathrm{CO}_{2}$, condensable vapors, and organic acids between $200-280^{\circ} \mathrm{C}$ (Sinha et al. 2000). Organic acids especially acetic acid formation acts as depolymerization catalyst and increase the decomposition of polysaccharides (Brosse et al. 2010, Esteves and Pereira 2008). Until the temperature reached $370^{\circ} \mathrm{C}$, other components continued to degrade. At higher temperature, charring reaction occurred. As seen in Table 2, residual char content and $\mathrm{T}_{\max }$ values were calculated as $33 \%$ and $353^{\circ} \mathrm{C}$ respectively for the untreated sample.

Table 2. The temperature of the initial weight loss of pyrolysis $\left(\mathrm{T}_{\mathrm{i}}\right)$, maximum degradation temperature $\left(\mathrm{T}_{\max }\right.$ and Residual char of AD KD-5, WCX-8, and TN-E impregnated Oriental beech wood.

\begin{tabular}{|c|c|c|c|c|}
\hline & Concentration & $\mathrm{Ti}\left({ }^{\circ} \mathrm{C}\right)$ & $\begin{array}{c}\text { Residual Char } \\
\text { Content } \%\end{array}$ & $\mathrm{~T}_{\max }\left({ }^{\circ} \mathrm{C}\right)$ \\
\hline \multirow{2}{*}{ CONTROL } & - & 231 & 33 & 353 \\
\hline \multirow{4}{*}{ AD KD-5 } & $0,25 \%$ & 229 & 41 & 332 \\
\cline { 2 - 5 } & $1,00 \%$ & 207 & 42 & 330 \\
\cline { 2 - 5 } & $4,70 \%$ & 182 & 54 & 327 \\
\hline \multirow{3}{*}{ TN-E } & $0,25 \%$ & 230 & 36 & 339 \\
\cline { 2 - 5 } & $1,00 \%$ & 226 & 38 & 339 \\
\cline { 2 - 5 } & $4,70 \%$ & 212 & 49 & 336 \\
\hline \multirow{3}{*}{ WCX-8 } & $0,25 \%$ & 216 & 35 & 333 \\
\cline { 2 - 5 } & $1,00 \%$ & 207 & 40 & 330 \\
\hline
\end{tabular}

TG, DTG and DTA curves of AD KD-5 WCX-8, and TN-E impregnated Oriental Beach wood with various concentration are seen in Figure (a1, b1 and c1); (a2, b2 and c2) and (a3, b3 and c3) respectively. Below $200^{\circ} \mathrm{C}$, no observable changes could be seen in TG curves of all commercial wood preservative treated samples but as same in DTG curves of untreated wood sample endothermic peaks at nearly $80-110^{\circ} \mathrm{C}$ were observed in figure c1, $\mathrm{c} 2$ and $\mathrm{c} 3$ for all concentrations, and for all treated wood samples, exothermic peaks between $340-350^{\circ} \mathrm{C}$ were seen. These peaks arisen from the transition of amorphous $\mathrm{B}_{2} \mathrm{O}_{3}$. Although crystalline boronoxide melt at $450^{\circ} \mathrm{C}$, it was reported that the amorphous boron oxide soften at $325^{\circ} \mathrm{C}$ (Sevim et al. 2006). In Table 1, the composition of wood preservatives is listed. From the table, it is easily seen that there are small amounts of boric acid in AD KD-5, WCX8, and TN-E. As seen in DTG curves (Figure b1, b2 and b3) degradation rates decreased with the increasing concentration of AD KD-5, WCX-8, and TN-E. $\mathrm{T}_{\mathrm{i}}$, residual char content, and $\mathrm{T}_{\max }$ values of AD KD-5, WCX-8, and TN-E treated wood samples are listed in Table 2. As seen in the Table, initial degradation temperature decreased with the increasing of applied concentrations. Residual char content of all treated wood sample were higher than untreated wood sample and residual char content of treated wood sample increased with increasing applied preservative concentration. $\mathrm{T}_{\max }$ values were found 
inversely proportional with the increasing concentration of AD KD-5, WCX-8, and TN-E.

As seen in Table 2, proportional with the boric acid content of wood preservatives, residual char contents of 4,70\% AD KD-5, WCX-8, and TN-E impregnated wood sample were found 54, 49, and $49 \%$ respectively. Commercial wood preservative includes $\mathrm{Cu}$ and pesticides for protecting wood from fungus and other pest. They also included boric acid which is also known as flame retardant. Presences of borates caused formation of a protective layer and protects the wood from high temperatures. Because of these reasons, the char amount of treated Oriental beech wood increased with respect to untreated sample. It was thought that the residual char content was in good agreement with the boric acid amount in wood preservatives. It was reported that the inorganic salts change the pyrolysis process depending on the salt type and substrate. Metals, metal salts or metal complexes in the formulations of wood preservatives applied on woods increase char yield (Tomak et al. 2012).

\section{CONCLUSIONS}

Pyrolysis of Oriental beech sawdust treated with 0,$25 ; 1$ and 4,70\% aqueous solutions of AD KD-5, WCX-8, and TN-E was monitored by thermogravimetric analysis under argon atmosphere in this study. Thermogravimetric analysis (TG), differential thermogravimetric analysis (DTG), and differential thermal analysis (DTA) were discussed in this article.

Our results showed that increase in applied concentration of boric acid containing wood preservatives decreased the $\mathrm{T}_{\max }$ (maximum degradation temperature) and increased residual char amount. Residual char contents of the treated wood sample were higher than untreated wood sample. The highest residual char content was found for the sample treated with 4,70\% AD KD-5 among the all treated wood sample. Residual char content of preservative treated wood sample at fixed concentration of $4,70 \%$ ranked as in the following order: AD KD-5> WCX-8 and TN-E $>$ Control. It was also found that $T_{i}$ values was lower than the untreated wood sample.

In this work, we focused on thermal characteristics of Oriental beech sawdust samples and effects of preservatives on structural constituents during the heat treatment. So, homogenity of the wood samples was important because of the reliability of the result. It is clear that the desired homogenity could not be achieved when the solid wood is used. Thermal characteristic of preservative treated solid wood should be tested for actual effects of heat on wood products. The thermo-gravimetric analysis is fast, efficient and effective way to test the performance of the chemicals against fire. But still combustion tests and/ or limited oxygen index test (LOI) should be done for better understanding of behavior of chemicals against the fire. For the further investigations, gas products of pyrolysis should be investigated for better understanding. 


\section{ACKNOWLEDGEMENTS}

The design and development of study was proposed by Ergun Baysal. Ergun Baysal and Ilyas Deveci carried out thermal analysis and interpretation of the analysis. Turkay Turkoglu and Hilmi Toker contributed to the writing, revising and proofing of the paper. Extensive advice and critique of the research was provided by Ilyas Deveci and Ergun Baysal.

\section{REFERENCES}

Ahmed, S.A.; Morén, T. 2012. Moisture properties of heat-treated Scots pine and Norway spruce sapwood impregnated with wood preservatives. Wood and Fiber Science 44(1): 85-93.

Ajuong, E.; Pinion, L.C. 2010. Corrosion and degradation of engineering materials. In Shreir's Corrosion, Editor-in-Chief: Tony J.A. Richardson, Elsevier Science Ltd, pp. 2439-2446.

Archer, K.; Preston, A. 2006. An overview of copper based wood preservatives. Wood protection 2006. [online] <http://www.forestprod.org/wood protection06archer.pdf $>$ [cited ]

Baysal, E. 2002. Determination of oxygen index levels and thermal analysis of Scots pine (Pinus sylvestris L.) impregnated with melamine formaldehyde-boron combinations. Journal of Fire Sciences 20(5): 373-389.

Bhat, I.U.H.; Abdul Khalil, H.P.S.; Awang, K.B.; Bakare, I.O.; Issam, A.M. 2010. Effect of weathering on physical, mechanical and morphological properties of chemically modified wood materials. Materials and Design 31(9): 4363-4368.

Brosse, N.; EL Hage, R.; Chaouch, M.; Pétrissans, M.; Dumarçay, S.; Gérardin, P. 2010. Investigation of the chemical modifications of beech wood lignin during heat treatment. Polymer Degradation and Stability 95(9): 1721-1726.

Chandrasekaran, S.R.; Hopke, P.K. 2012. Kinetics of switch grass pellet thermal decomposition under inert and oxidizing atmospheres. Bioresource Technology 125: 52-58.

Deka, M.; Saikia, C.N.; Baruah, K.K. 2002. Studies on thermal degradation and termite resistant properties of chemically modified wood. Bioresource Technology 84(2): 151-157.

Di Blasi, C. 2008. Modeling chemical and physical processes of wood and biomass pyrolysis. Progress in Energy and Combustion Science 34(1): 47-90.

Esteves, B.; Pereira, H. 2008. Wood modification by heat treatment: A review. BioResources 4: $370-404$ 
Freeman, M.H.; Mcintyre, C.R. 2008. Copper-based wood preservatives. Forest Products Journal 58(11): 6-27.

Gao, M.; Zhu, K.; Sun, Y.G. 2004. Thermal degradation of wood treated with amino resisns and amino resins modified with phosphate in nitrogen. Journal of Fire Sciences 22: 505-515.

Gao, M.; Ling, B.; Yang, S.; Zhao, M. 2005. Flame retardance of wood treated with guanidine compounds characterized by thermal degradation behavior. Journal of Analytical and Applied Pyrolysis 73(1): 151-156.

Helsen, L.; Van den Bulck, E. 2005. Review of disposal technologies for chromated copper arsenate (CCA) treated wood waste, with detailed analyses of thermochemical conversion processes. Environmental Pollution 134(2): 301-314.

Jiang, J.; Li, J.; Hu, J.; Fan, D. 2010. Effect of nitrogen phosphorus flame retardants on thermal degradation of wood. Construction and Building Materials 24(12): 2633-2637.

Jiang, J.; Li, J.; Gao, Q. 2015. Effect of flame retardant treatment on dimensional stability and thermal degradation of wood. Construction and Building Materials 75: 74-81.

Kiziltas, A.; Gardner, D.J.; Han, Y.; Yang, H.S. 2011. Dynamic mechanical behavior and thermal properties of microcrystalline cellulose (MCC)-filled nylon 6 composites. Thermochimica Acta 519(1): $38-43$.

Lesar, B.; Pavlič, M.; Petrič, M.; Škapin, A.S.; Humar, M. 2011. Wax treatment of wood slows photodegradation. Polymer Degradation and Stabilization 96(7): 1271-1278.

Liodakis, S.; Bakirtzis, D.; Dimitrakopoulos, A.P. 2003. Autoignition and thermogravimetric analysis of forest species treated with fire retardants. Thermochimica Acta 399(1): 31-42.

Lowden, L.A.; Hull, T.R. 2013. Flammability behaviour of wood and a review of the methods for its reduction. Fire Science Reviews 2(1): 1-19.

Mourant, D.; Yang, D.Q.; Riedl, B.; Roy, C. 2008. Mechanical properties of wood treated with PF-pyrolytic oil resins. Holz als Roh- und Werkstoff 66(3): 163-171.

Palanti S, Predieri G., Casoli A., Vignali F., Feci E 2008 New preservatives based on copper chelates and copper complexes grafted to functionalized silica gel, Cost Action E37 Final Conference in Bordeaux 2008, Socio-economic perspectives of treated wood for the common European market, 23-29

Palanti, S.; Predieri, G.; Vignali, F.; Feci, E.; Casoli, A.; Conti, E. 2011. Copper complexes grafted to functionalized silica gel as wood preservatives against the brown rot fungus Coniophora puteana. Wood Science and Technology 45(4): 707-718.

Poncsák, S.; Kocaefe, D.; Bouazara, M.; Pichette, A. 2006. Effect of high temperature treatment on the mechanical properties of birch (Betula papyrifera). Wood Science and Technology 40(8): 647663. 
Salca, E.A.; Hiziroglu, S. 2014. Evaluation of hardness and surface quality of different wood species as function of heat treatment. Materials and Design 62: 416-423.

Salman, S.; Pétrissans, A.; Thévenon, M.F.; Dumarcay, S.; Perrin, D.; Pollier, B.; Gérardin, P. 2014. Development of new wood treatments combining boron impregnation and thermo modification: effect of additives on boron leachability. European Journal of Wood and Wood Products 72(3): 355365.

Sevim, F.; Demir, F.; Bilen, M.; Okur, H. 2006. Kinetic analysis of thermal decomposition of boric acid from thermogravimetric data. Korean Journal of Chemical Engineering 23(5): 736-740.

Sinha, S.; Jhalani, A.; Ravi, M.; Ray, A. 2000. Modelling of pyrolysis in wood: A review. SESI Journal 10: 1-17.

Tomak, E.D.; Baysal, E.; Peker, H. 2012. The effect of some wood preservatives on the thermal degradation of Scots pine. Thermochimica Acta 547: 76-82.

Tsujiyama, S.I.; Miyamori, A. 2000. Assignment of DSC thermograms of wood and its components. Thermochimica Acta 351(1): 177-181.

Turkoglu, T.; Baysal, E.; Toker, H. 2015. The effects of natural weathering on color stability of impregnated and varnished wood materials. Advances in Materials Science and Engineering vol. 2015, Article ID 526570: 1-9.

Uner, I.H.; Deveci, I.; Baysal, E.; Turkoglu, T.; Toker, H.; Peker, H. 2016. Thermal analysis of Oriental beech wood treated with some borates as fire retardants. Maderas- Cienc Tecnol 18(2): 293304.

Wang, Q.; Li, J.; Wınandy, J. E. 2004. Chemical mechanism of fire retardance of boric acid on wood. Wood Science and Technology 38(5): 375-389.

White, R.H.; Dietenberger, M.A. 2001. Wood products: thermal degradation and fire. In Encyclopedia of Materials: Science and Technology, Editors-in-Chief: K.H. Jürgen Buschow, Robert W. Cahn, Merton C. Flemings, Bernard Ilschner, Edward J. Kramer, Subhash Mahajan, and Patrick Veyssière, Elsevier Science Ltd, pp. 9712-9716.

Wielage, B.; Lampke, T.; Marx, G.; Nestler, K.; Starke, D. 1999. Thermogravimetric and differential scanning calorimetric analysis of natural fibres and polypropylene. Thermochimica Acta 337(1): 169-177.

Wu, Y.; Yao, C.; Hu, Y.; Yang, S.; Qing, Y.; Wu, Q. 2014. Flame retardancy and thermal degradation behavior of red gum wood treated with hydrate magnesium chloride. Journal of Industrial and Engineering Chemistry 20(5): 3536-3542.

Yorulmaz, S.Y.; Atimtay, A.T. 2009. Investigation of combustion kinetics of treated and untreated waste wood samples with thermogravimetric analysis. Fuel Processing Technology 90(7): 939-946. 
Yunchu, H.; Peijang, Z.; Songsheng, Q. 2000. TG-DTA studies on wood treated with flameretardants. Holz als Roh-und Werkstoff 58(1-2): 35-38. 